\title{
Time, Culture and Identity: Exploring Horological Collections with UK-China Museum Audiences
}

\author{
Carol CHUNG 钟珞筠1
}

(Science Museum, London SW7 2DD, UK)

\begin{abstract}
This paper discusses cross-cultural understanding of museum collections by looking into transnational audience engagement with the imperial clock collection of the Palace Museum in Beijing. The audience research took place in three sites: the Hong Kong Science Museum, the Palace Museum in Beijing, and the Science Museum in London. Audience data were collected using qualitative methods, such as intercept interviews, focus groups, and informal group discussions with non-specialist and specialist audiences across the three locations. The qualitative samples suggest that UK-China audiences draw from different cultural references when they engage with the unique "singsongs" in the imperial clock collection. Despite the divergence of cultural connections made across audiences in the UK and China, it is consistent in the audience data that the appeal of the clocks is reinforced by seeing their movement. The data also indicate a desire to connect with human stories behind the creation, trade, and conservation of singsongs, and expectations for a digital resource that is visually captivating and offers additional insights into the singsongs, such as the demonstration, mechanism, and backstory of the automatons. This paper concludes with a reflection on the implications of audience data for the interpretation strategy of a London-based exhibition featuring the singsongs, and considerations for the development of a digital experience about the imperial horological collections that speaks to audiences across the UK and China.
\end{abstract}

Keywords: audience engagement, Palace Museum, interpretation, singsongs, mechanical clocks

\section{Introduction}

$\mathrm{I}_{\mathrm{i}}^{\mathrm{n}}$

the eighteenth century, mechanical clocks and automatons were unique, key trade items exported from Britain to China. These large and elaborate decorative works,

Received: July 27, 2020. Revised: October 4, 2020.

1 Postdoctoral Research Associate. Research interests: Museum and heritage interpretation, audience research, cross-cultural collaboration in museum and heritage. Email: carol.chung@ sciencemuseum.ac.uk 
which contained clocks, automatons, and music boxes, were known as "singsongs," an anglicization of their Chinese name, zimingzhong (自鸣钟), meaning "self-sounding bells" (Pagani 2001).

Singsongs were made by networks of hundreds of specialist craftsmen working in London and the north of England. They had elaborate designs which were intended to appeal to the Chinese market (White 2012). Once complete, singsongs traveled from London to Guangdong, often via India, as private trade goods on East India Company ships. Many made their way from Guangdong to the imperial palace in Beijing as tribute gifts to the emperor of China, whilst others were bought by or gifted to senior officials and the elite (Zhang and Cai 2018). As complex mechanical objects, singsongs needed to be regularly repaired and maintained. Horological workshops, known as the imperial workshops (zaobanchu 造办处), were established within the Forbidden City. Jesuit missionary craftsmen worked alongside Chinese craftsmen to repair, maintain, and later to adapt and make singsongs for the emperor (Guo 2013). By the late eighteenth century, craftspeople in southern China were making their own singsongs for a range of consumers, from the emperor to wealthy merchants (Guo 2013; Zhang and Cai 2018).

Today the Palace Museum in Beijing cares for the Forbidden City and the collections of the Chinese emperors, including around 1500 singsongs made in Europe and China. In 2018, the Science Museum, in partnership with the Palace Museum, Chinese Academy of Sciences, and Beijing Jiaotong University, began to explore the little-known story of British and Chinese singsongs, their production and trade, and the encounters between people from different nations.

The project "Time, Culture and Identity: The Co-Creation of Historical Research and Co-Development of Visitor Experience in China and the UK" united expertise and collections from these two countries to explore the Palace Museum's collection of eighteenth-century clocks, watches, and automatons, and the social, cultural, and technological impacts they have had in China and Britain. The project team conducted collaborative archive research into the imperial clock collection and codeveloped a digital heritage product with creative businesses in Britain and China to help audiences engage with the imperial clock collection. The project was funded by a grant awarded to the Science Museum from the UK's Arts and Humanities Research Council and the Newton Fund, and the project ran from December 1, 2018 to April 30, 2020.

A key aim of the project, as part of the collaborative research program about the imperial clock collection, was developing a cross-cultural understanding of Chinese and British museum audiences in terms of their requirements and expectations of a digital heritage experience. Focusing on understanding the way visitors in China and Britain engage with historical clocks, the project sought to answer the question: "How does visitor engagement differ and/or converge between British and Chinese 
audiences?" The project team commissioned a consultant to carry out audience research in three locations: Hong Kong, Beijing, and London. Findings of this transnational audience research will help museum and heritage professionals explore methodologies and approaches to support the cultural understanding of the creation of digital interpretation and enhance the understanding of museum interpretive styles in China and Britain.

This paper will first review key literature in visitor research, and museum and heritage interpretation, followed by a section on the design and method of the transnational audience research. It then turns to a discussion of findings drawn from audience research data. The paper concludes with implications for audience interpretation needs and audience expectation for a digital experience that engages with the imperial horological collections.

\section{Audience engagement with museum objects}

Research exploring visitor use and engagement with museum collections is still in its infancy (Black 2012). Museum studies literature has identified that "object experience" is an important component of a satisfying experience among museum visitors (Pekarik, Doering, and Karns 1999). Object experience centralizes an object-focused fascination that contributes to satisfaction because of the intrinsic qualities of objects. A parallel discussion on "numinous experience" further links object experience with two other types of visitor experience: the cognitive experience and the introspective experience (Pekarik, Doering, and Karns 1999). Numinous experience refers to the quest for a deeper experience and a desire to make a personal connection with the people and spirit of earlier times through visiting original historical sites and objects (Cameron and Gatewood 2003). A numinous encounter is a holistic uniting of intellect and emotion, with a direct link to the tangible and symbolic nature of the object, a feeling of being transported, and an intensely profound connection with the past, self, and spirit (Latham 2013). These studies suggested a strong link with the concept of authenticity, with which museums and heritage sites were strongly associated in the sense that they create access to relics of the past or items of wonder (Prentice 2001) and offer an "authentic experience" that links the past and present through contact with artifacts and lives (Leary and Sholes 2000). Authenticity is very relevant to the discussion of scientific and technological collections in museums. Research further revealed four dimensions of authentic objects in science museums: history, charisma, rarity, and functionality (Hampp and Schwan 2015). Authentic objects connect visitors with history, deliver senses of "rarity" and "charisma," and in some cases generate insights for the materiality and functionality of an object in a given time.

Researchers, however, caution the danger of assuming that access to real objects or 
sources is transformative and have highlighted the need to consider object knowledge and museum literacy in relation to authenticity (Bain and Ellenbogen 2002). Whilst transmitting knowledge has given way to meaning-making in the museum, authenticity has become less essential to learning in comparison with the potential to support participation (Eberbach and Crowley 2005). Studies that discussed the diminishing role of museum objects further noted that in the latter half of the twentieth century museums moved away from a stage where objects were the sole focus of displays and no mediation was required to disseminate the knowledge they embodied, towards a visitor-oriented stage where objects were the vehicles for visitor experience (Macdonald 1998; Roberts 1997). These insights lead us to think that in object-based exhibitions - particularly in museums of science and technology - the focus often tends to be on what the object does and the ideas behind it, rather than the object itself. Visitors show as much interest in seeing the objects as in learning about the contextthe sociocultural significance, the function, the personal stories (for example, who invented this?)-around the objects. Failure to provide contextual information for visitors may cause a barrier to engagement with objects.

\section{Chinese audiences and their interpretive preferences}

Visitors come to museums to learn about things by relying on their conceptual frameworks - prior knowledge and experience-to understand what they encounter (Falk and Dierking 2013). How audiences interpret museum collections-specifically, how they make sense of an object-is key to the discussion of audience engagement with historical collections. Seasoned and novice museum visitors differ by their frame of reference, which is influenced by education, interest, experiences and, very often, cultural background (Falk and Dierking 2013). Understanding the interest, prior knowledge, and cultural positions and values of the visitors is key to the creation of interpretive materials for the museum and heritage sector. In particular, the roles of cultural value and cultural position in heritage and museum interpretation are highly relevant to the study of transnational audience engagement, which is a key remit of the Time, Culture and Identity project.

Studies that seek to understand Chinese perceptions of cultural heritage - in both its tangible and intangible forms - have identified that the interpretive needs of visitors are heavily informed by China's extensive historical and cultural background, a large element of which has been strongly influenced by the development of the Chinese language and the introduction of Confucianism and Taoist philosophies (Ballantyne et al. 2014; Fu, Cai, and Lehto 2017; Kwek and Lee 2010; Xu, Ding, and Packer 2008; Xu et al. 2013). Underpinned by Confucianism, Chinese cultural values have been shaped by a philosophy that venerates the depiction of cultural landscapes and heritage sites 
through art, poetry, and calligraphy. Thus, such representations become a vessel for passing on specific values, morals, and beliefs from generation to generation (Ballantyne et al. 2014; Petersen 1995). In this instance, Chinese heritage is heavily imbued with a strong cultural significance, whereby the representation of heritage sites or artifacts is often tied to an aesthetic approach, such as storytelling, art, or folklore (Gao, Zhang, and Huang 2018; Sofield and Li 1998).

Research that explores emphasis on the interrelationship between humans and the environment-as part of Taoist teachings-further confirms the role of traditional philosophy in making interpretations among Chinese visitors (Fu, Cai, and Lehto 2017). Drawing from the Taoist philosophy that reinforces the relationship between nature and humanity (Yan 2017), human-environment relationships are integral to Chinese visitors' interpretation of heritage. Studies have found that Chinese visitors desire to better understand human relations with heritage landscapes, and particularly, the manner through which built heritage may enhance the heritage experience (Winter 2009; Ballantyne et al. 2014). Furthermore, studies that focus on "authenticity", a concept that is considered a key influencer of the tourist experience, confirm that the Chinese view of authenticity is associated with the physical, spiritual, aesthetic, and social qualities of a particular site or cultural landscape (Xu, Ding, and Packer 2008; Yi et al. 2017). In this sense, what gives credence to the authenticity of heritage sites or artifacts is not only its physical presence, but the cultural values attached to it through cultural medium, such as the literary work.

In brief, to understand the consumption and interpretation of museum collections, there is a need to consider the visitor as an active agent capable of making meanings in relation to their own positionality. Attention should be placed upon an approach to the consumption of cultural products that incorporates both talking and listening to visitors in order to fully capture interpretive perceptions. Moreover, to understand the nuances and complexities of making sense of cultural products, an approach is required that can understand visitors' interests, and their own cultural position (Poria, Biran, and Reichel 2009, 103).

\section{Audience research background}

As stated above, the Time, Culture and Identity project aims to understand the ways in which visitor engagement with the imperial clock collection differ and converge in the context of a UK-China research collaboration. Such understanding contributes to the development of a codesigned digital heritage product that aims at appealing to international audiences. In this sense, whilst the project sought to gain cultural understanding of the interpretation needs of audiences across China and the UK, there was a practical focus of using audience research to find out about the requirements for 
the digital heritage product. This research would then inform the creative brief for UKChina creative businesses collaborating on the development of a digital product related to the imperial clock collection. With the context in mind, the key objectives for audience research were:

- To ascertain how interests in the collection converge/vary according to gallery and exhibition location.

- To establish levels of knowledge on horology, distinguishing between enthusiasts and/or non-enthusiasts.

- To identify the audience for a digital resource exploring the imperial clock collection.

- To define the expectations for a digital resource exploring horology and related themes.

The audience research employed primarily qualitative methodology. A variety of qualitative methods were used to acquire visitor data, taking the form of focus groups, informal group discussions, in-depth interviews with experts and influencers, and intercept interviews in three locations. For clarity, focus groups were semi-structured ninety-minute sessions of seven to nine participants. Informal group discussions were informal meetings with variable numbers of participants.

Quantitative analysis was used to supplement the qualitative analysis, and relied primarily on existing audience data available from the host museum. The project team had access to general visitor entry data for the Palace Museum and the Hong Kong Science Museum (HKSM). The HKSM also initiated its own survey specifically of visitors to Treasures of Time, achieving a sample of over nine hundred participants. This was supplemented by an appendix survey of over fifty interviews using a questionnaire codesigned by the consultant and the HKSM team.

\section{Research sites}

Three research sites were selected for the project: the Palace Museum (Beijing), the Hong Kong Science Museum (Hong Kong), and the Science Museum (London). Audience evaluations were devised and conducted to gain understandings of the awareness of, interest in, and response to the imperial collection across the three sites. Each site represented different audience groups and brought in a different representation of the imperial clock collection, as discussed below.

The HKSM is extremely popular and well known as a family-friendly, hands-on museum of science. A temporary exhibition, Treasures of Time, which was open from December 7, 2018 to April 10, 2019 and showcased the imperial clocks from the Palace Museum, was selected for the research in Hong Kong. The temporary exhibition was a strategy initiative presenting the HKSM as also catering for adult tastes whilst 
remaining an important site for education groups.

The Palace Museum in Beijing is one of the most visited museums in the world. The Hall of Clocks and Watches at the museum was selected as the research site in Beijing. Recent refurbishment has refreshed the hall, but it only has the capacity to show a modest selection from the entire clock collection. Most visitors interviewed for the project were likely to be tourists attempting to see the vast Forbidden City in one visit. The context of the palace has influenced visitors' perceptions, as the imperial clocks were seen as the possessions of a resident emperor.

The London Science Museum's forthcoming temporary exhibition Zimingzhong 自鸣钟: Clockwork Treasures from China's Forbidden City will feature twenty-five clocks from the imperial clock collection. Audience evaluation, therefore, was a formative process, in which discussions considered implications for the creation of the digital resource and marketing angles for the forthcoming exhibition. The Science Museum as host and collaborator inescapably influences visitors' perceptions and expectations.

\section{Data collection}

Qualitative data were collected through international fieldwork that took place between March and June 2019, with two trips to Hong Kong and one trip to Beijing. In total, four days were spent working with the audience research team at the Palace Museum in Beijing and eight days in Hong Kong across two trips. The London fieldwork took place in April 2019, and included two focus groups, interviews, and desk-based research. The qualitative samples achieved through fieldwork across Hong Kong, Beijing, and London were as follows. For the intercept interviews they were:

- Twenty-eight intercept interviews with visitors to the Treasures of Time exhibition at the HKSM, Hong Kong (Figure 1).

- Thirty-five intercept interviews with visitors to the Hall of Clocks and Watches, Palace Museum, Beijing (Figure 2).

The samples for focus groups (Figure 3) were:

- Two focus groups-one with young Hong Kong residents and one with international visitors - conducted with a thirty-minute tour of the Treasures of Time exhibition at the HKSM, Hong Kong.

- One focus group with Beijing Jiaotong University students primarily majoring in mechanical engineering, conducted with a pre-visit to the Hall of Clocks and Watches, Palace Museum, Beijing. 
- One focus group with horological experts, watchmakers, collectors, and academics at the Science Museum, London.

- One focus group with young exhibition-goers (aged between twenty and thirty) at the Science Museum, London.

- One focus group with docents who gave guided tours of the Treasures of Time exhibition at the HKSM, Hong Kong.

- One focus group with visitors to the Treasures of Time exhibition at the HKSM, Hong Kong.

The samples for informal group discussion were:

- One informal group discussion with Hong Kong collectors, who attended lectures and tours of the Treasures of Time exhibition at the HKSM, Hong Kong.

- One informal group discussion with jewelers at House of Garrard, London.

- One informal group discussion with five volunteers who regularly work in the Hall of Clocks and Watches, Palace Museum, Beijing.

Quantitative data were provided by host destinations in Beijing and Hong Kong, which were readily available visitor data collected by the Palace Museum and the HKSM. In Beijing, visitor data focused on total visitor numbers to the Forbidden City. Identifying visitors specifically intending to visit the Hall of Clocks and Watches was challenging. It can be assumed that many visitors include the Hall of Clocks and Watches as one element of their visit rather than as a specific destination. In comparison, the HKSM undertook a detailed exit survey specifically of the visitors to the Treasures of Time temporary exhibition, which achieved a sample of just over 905 interviews. It measured visitor interest, scored appreciation indices and outcomes, and recorded responses to interpretive approaches.
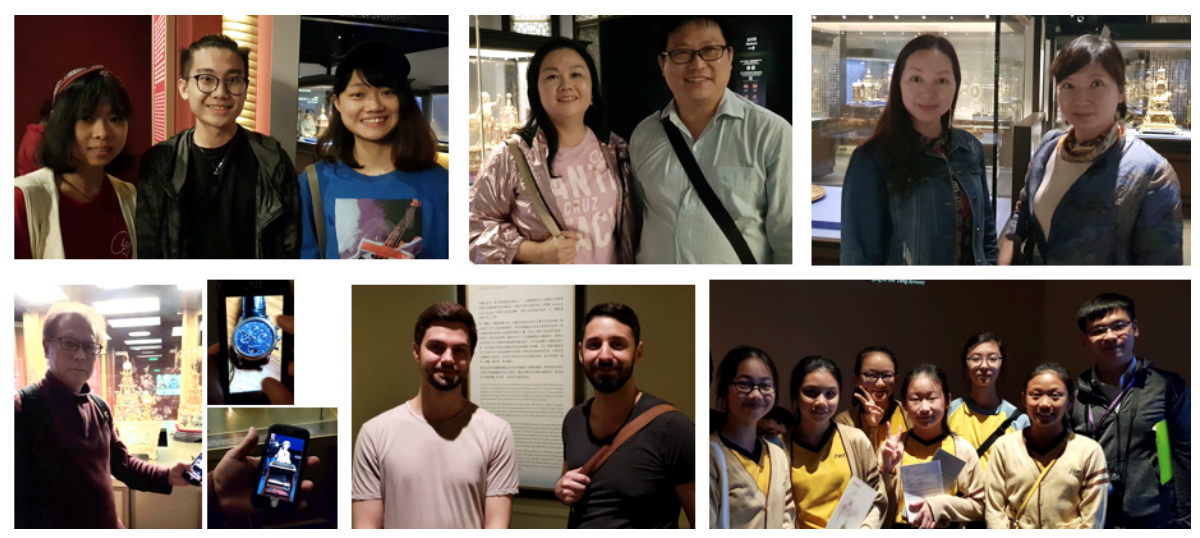

Figure 1: Intercept interviews with visitors at the HKSM (photo by Terry Watkins). 

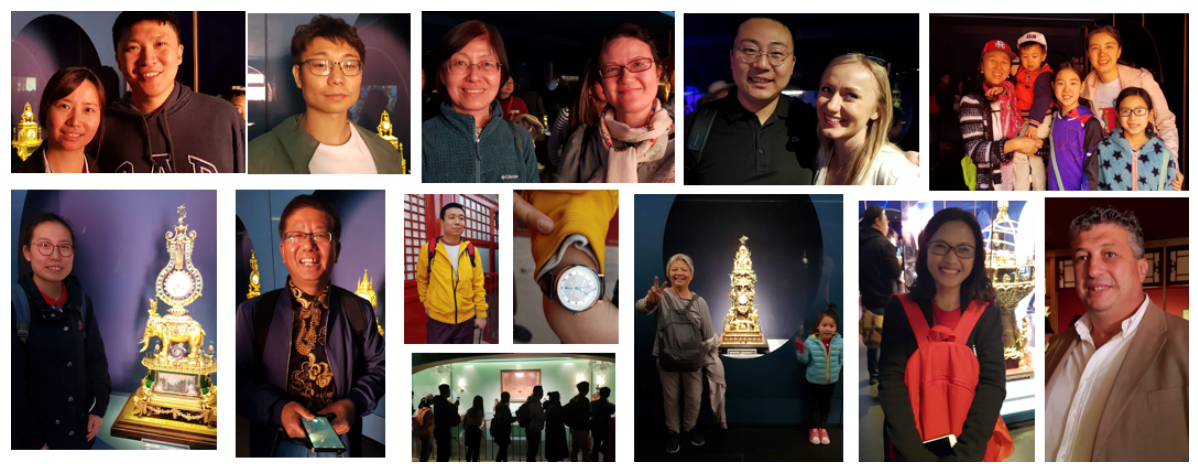

Figure 2: Intercept interviews with visitors at the Palace Museum, Beijing (photo by Terry Watkins).

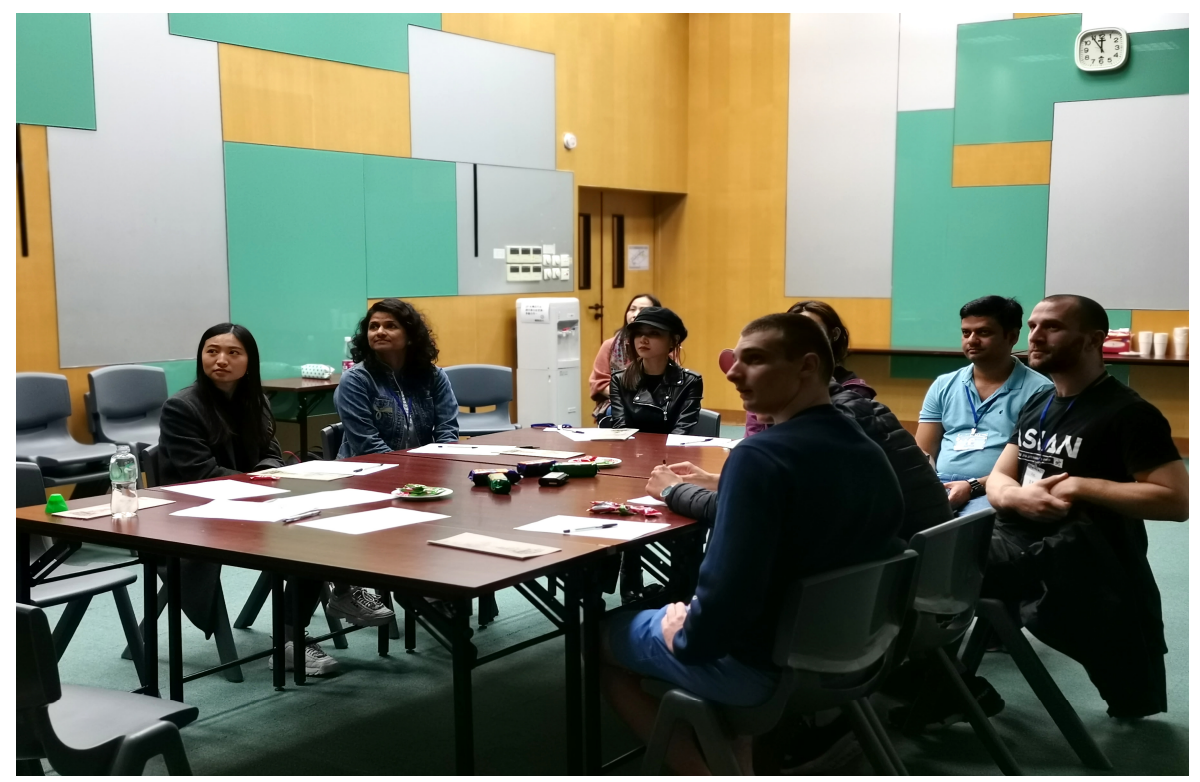

Figure 3: Focus groups with audiences in Hong Kong, Beijing, and London (photo by Terry Watkins).

\section{Findings and discussions}

In this paper I draw findings exclusively from the qualitative sample. Qualitative data were first analyzed by the consultant and revisited by the Time, Culture and Identity project team for the purpose of writing up this paper. Findings are reported against the research objectives outlined above. In this section, I report findings that highlight the following themes: audience interest in the imperial clock collection-how and why interest differs and converges among the audiences across the three research sites; audience interpretation and behavior across the three research sites; and audience 
expectations for a digital resource exploring the imperial clock collection.

\subsection{Interest in the imperial clock collection}

Visitors to museums and galleries bring with them their existing knowledge, experience, and cultural associations (Falk and Dierking 2013). They are more likely to connect with objects that they recognize, and that are culturally familiar to them. In the case of clocks, there are very different cultural associations and implications in the UK and China. In Chinese, "giving a clock" (songzhong 送钟) sounds very similar to the words for "attending a funeral ritual" (songzhong 送终). It is therefore considered bad luck to give a clock as a gift in China, particularly to anyone confronting their own mortality and conscious that life is ticking away. In comparison, in the UK, rewarding years of loyal service with the gift of a clock is the clichéd gift of retirement.

A collection of eighteenth-century clocks once belonging to the Chinese emperors can appear to be a niche subject that will primarily appeal to enthusiasts of timepieces. However, our findings suggest that interest significantly increases beyond the specialist audience with the appreciation that many of the clocks are working automatons with animated scenarios that are integral to their elaborate design. When interest is stimulated, questions focusing on the context of creation and the mechanics of clockworks arise among the audiences. There is also a strong desire to see the inner workings of the clocks and to understand how they work, which are consistent outcomes of the curiosity the clocks generate.

\subsubsection{Cultural connections with the imperial clocks}

Despite the overall interest in the imperial clock collection, different cultural associations were found among audiences across China and the UK. Cultural factors specific to Chinese and British audiences result in different points of connection (Ballantyne et al. 2014). The elaborate design, luxurious decorations, and the overall aesthetics of the clocks are more appealing to Chinese audiences than UK audiences, whilst in the UK interest focuses on James Cox-maker of the elaborate clocks and automatons in the imperial collection - and the eighteenth-century trading relationship with China.

Findings suggest that visitors in China and Hong Kong of Chinese citizenship or heritage often overlook the significance of the trading relationship with the UK and the James Cox episode of the story. The collection, for Chinese visitors, reflects the wealth and discernment of the Chinese emperor, who both sourced clocks internationally and inspired the creation of a comparable Chinese school of clock production. For example, visitors in China and Hong Kong often perceived the imperial clocks to be a collection of "treasures to display" more than "novelties that perform." These impressions are 
fueled by the implied preciousness of static presentation in museum glass cases and the necessities of preservation, protection, and abundant decoration, with an implication that the clocks are made of precious jewels and valuable materials. Moreover, words such as "magic," "novelty," "whimsy," and "delightful" were used to describe the clocks among specialist/enthusiast audiences in the Hong Kong collectors circle discussion group. In comparison, non-specialist audiences at the HKSM made more references to "jewels," "precious," and "valuable." While the luxury aesthetic of the imperial clocks immediately catches the eyes of audiences, it prompts the curiosity of a wide audience to explore beyond the elaborate design and detailed, sophisticated materiality of the clocks:

I noticed that the clocks are from France, Britain, and Switzerland. I noticed that there are differences between the designs, in particular the French ones are more imaginative. They have things like a light tower and a balloon. The British ones are splendid and sophisticated. There are repeat designs like the elephant and the pineapple, which made me wonder why they were favorites. Was it for India? So, I'm prompted to be curious about the history and culture behind the designs of the clocks. (Engineering student focus group, Beijing Jiaotong University)

In contrast, there is a greater interest in the UK in the clocks from the business and workshop network of James Cox and in the eighteenth-century trading relationship between Britain and China. The fantastic designs, entertaining and sophisticated mechanisms, and the connections and ramifications of the story extend the appeal beyond the narrow focus of the timepiece academics and enthusiasts. The story of clock trades and the collection is considered a fascinating discovery, yet there is anecdotal digression from established specialisms and dominant narratives of horological history, as demonstrated by the following quotes:

I think the story of this is far bigger than clocks. It is about the relationships between countries, where people didn't understand each other and made assumptions about each other, and this is expressed in this weird world of fantasy clocks. (Horological specialists and timepiece enthusiasts focus group, London)

I find it interesting that they [British clockmakers] created this world but were never there. The automata have so many facets to interest so many different people. You have the internal workings, the art side, the stories behind them. That's why they're such a good thing. One object can tell a multitude of stories. (Horological specialists and timepiece enthusiasts focus group, London)

Moreover, the appeal of the clocks is reinforced by seeing the demonstration of the automatons, and the visitor's imagination is captured by seeing and appreciating the automatons, which resonates with existing studies of engagement with science 
collections (Hampp and Schwan 2015). This factor is more important in the UK, where the decoration and aesthetic of the clocks does not necessarily appeal to the taste of the UK audience, and where collections and galleries dedicated to clocks can seem a dry domain specifically catering for clock enthusiasts, as highlighted in the following quotes:

I don't think any of the clocks are interesting or attractive as clocks, but what they do is fascinating from an engineering and an artistic perspective. The challenge is getting members of the public to engage with what many might initially consider to be elaborate but ironically boring objects. (Horological specialists and timepiece enthusiasts focus group, London)

If I think of collections of clocks, I think of old people in tweed jackets and stuffy Antiques Roadshow [the UK TV program]. Seeing them working and their mechanism makes them interesting and stops them being antiques. (Young museum-goer focus group, London)

Although our findings indicate diverse points of connection through which the imperial clock collection sparked audience interest, there was a consistent and significant interest in the decoration of the clocks across Chinese and British audiences. Findings suggest that audiences in all locations wanted to know more about sources of inspiration and to have explanations of the characters, mythologies and astrological references that appear on the clocks. In many cases these are fantasy scenarios that merge references from the East and West, as shown in the following quotes:

Many of the clocks seem very Western in terms of mechanics and artistic look. It reminds me of the crazy mechanical devices in Dumbledore's office in the Harry Potter films. They are very imaginative devices. (Engineering student focus group, Beijing Jiaotong University)

The Chinese-made clocks show there is a different culture of time, mythology, and gods. When they have the exhibition in London there should definitely be clocks made in China, to give a more accurate reflection of the culture of China. (Engineering student focus group, Beijing Jiaotong University)

As the above quotes highlighted, visitors' own cultural background inevitably influences interpretation. It is a positive outcome of the cross-cultural collaboration that the decoration often evokes a connection with the familiar and equally prompts curiosity about the cultural significance of the visitor's source or destination culture (Gao, Zhang, and Huang 2018; Sofield and Li 1998).

Whilst "time" is ever present in this study, be it the clocks themselves or the added time that visitors spend with them, cultural views and measurement of time were not significant themes that stood out in the data analysis process. One explanation for the lack of data relating to visitor engagement with time and time measurement was the 
context of the three research sites. Only visitors who went to the Treasures of Time exhibition at the HKSM made comments relating to engagement with time measurement (or the lack of it), as it was part of the narrative running through the exhibition:

There's a bit of a disservice to the importance of clocks, the history of timekeeping and clockmaking. There are loads of really important historical moments where that's been essential, the dependence on clocks and timekeeping and that development. That wasn't really touched on. It was just look at these pretty clocks. (Young international focus group, HKSM)

While one visitor felt the lack of narratives on the history of timekeeping in the exhibition, other visitors appreciated and commented on the cultural significance of mechanical clocks and how different ways of measuring time changed the perception of time - at least for the Chinese emperor:

I like it being about two cultures interacting. China used to tell time in a very different way. One of the quotes from an emperor spoke about how accurate his clock was, and I thought to myself, that's a dramatic change in lifestyle. (Young international focus group, HKSM)

I didn't realize that clocks were introduced to China as early as the seventeenth century and that the emperors appreciated them and made poems for them. (Young international focus group, HKSM)

Although we found little evidence that painted a full picture of how visitors engaged with time through looking at the imperial clocks, we can be certain that visitors to the Treasures of Time exhibition had a grasp of the fact that different types of time were present here in the form of the time of the dynastic era and the time of modernity introduced from Europe, physically manifested in the forms of mechanical clocks. Within the historical context, understanding how visitors see the arrival of European modes of measuring time in China and how it changed Chinese views of time, both ancient and modern, will take this study to the next level and help us understand how visitors engage with clocks, and how such perceptions affect how visitors viewed and interpreted the clocks.

\subsection{Audience interpretation needs}

The visitor response to the imperial clock collection needs to be considered in the context of different and prospective host venues and environments (Black 2012). For visitors to the Palace Museum, the context of a palace gives special meaning to the collection as the valuable treasures of an emperor's home. Aligning with the discussion centering on visitors' cultural backgrounds that result in different points of connection (Ballantyne et al. 2014; Petersen 1995; Xu, Ding, and Packer 2008), visitors with an 
affinity with Chinese culture, whether from the Chinese mainland or of Cantonese heritage, were more likely to focus on and connect with the story of the emperor as collector rather than James Cox as creator. It is fair to say, from a Chinese perspective, that the quest to understand and measure time is more than the story of a seventy-year trading relationship with eighteenth-century Britain.

In comparison, visitors to a science museum expect to understand how clocks from a clock collection work. Our findings suggest that the added factor of the associations of host environment can further influence what is assumed to be the emphasis of interpretation and the expected priority of presentation in a particular exhibition environment. The quotes that follow demonstrate the way in which visitors to a science museum interpreted or expected to interpret the clocks and automatons from the imperial collection:

I was expecting it to be more based in the science of how it works: how innovation came from the UK and how it first influenced and then was incorporated in China. That doesn't come across at all and I'm not going to appreciate the fanciness of the art unless I have an anchor in the science of it. (Young international focus group, HKSM)

I thought they were presented beautifully as art, but if you were trying to present the scientific aspect of it that probably didn't come across so well. That's if you want to go into gears, how the mechanisms were developed. You would think they would, as we are in the Science Museum. (Young international focus group, HKSM)

I wanted to understand more about the role of time in people's lives, once they had these timepieces, but instead I got an art collection. (Young international focus group, HKSM)

Among younger museum-goers in the London focus group, there was also an assumption that an exhibition showcasing the imperial clock collections would be organized by a museum where the priority was history or decorative arts, such as the Victoria and Albert Museum. In this context, the Science Museum as host environment prompted the belief that the priority for interpretation would be objective explanation of the mechanics of operation. Alongside the cross-cultural connection, institutional framing of the particular museum plays an important role in helping visitors interpret the clocks. The Science Museum presents clocks as part of the history of science, and therefore frames clocks differently, compared with the way the British Museum or National Maritime Museum in Greenwich would do so. Meanwhile, in the Forbidden City, clocks form part of the former imperial collection. In Hong Kong, the clocks are again expected to give insights into the mechanical and engineering side of timekeeping, rather than being seen as a collection of art and historical artifacts of the trading relationship between Britain and China. 


\subsubsection{Human stories}

Accompanying accessible human stories help to stimulate empathy and engagement (Black 2012; Roberts 1997). The characters and connections may have differed between China and the UK, but the power of an accessible hero was evident throughout. Findings suggest that audiences across the UK and China all welcome human stories: in the UK this was the story of James Cox, whilst in China the China Central Television (CCTV) series featuring the conservators at the Palace Museum made a celebrity of the clock conservator, Mr. Wang Jin.

In China, the CCTV documentary Masters in Forbidden City was a major success. The China Daily described the essence of this success as follows: "the documentary does not dwell on the past. Instead, the camera focuses on the ordinary individual human beings - the restorers and their life in Beijing, which creates a bond between the audience and the restorer" (He 2016). The documentary made a media celebrity of the unassuming Mr. Wang Jin, horological conservator at the Forbidden City. In both Beijing and the HKSM, the series was cited as both inspiration and motivation for visiting the imperial clock collections. This can be deduced from the exit survey conducted by the HKSM, which suggested that over $50 \%$ of exhibition visitors were from the Chinese mainland, where the TV series was most likely to be a strong influence. Moreover, the documentary was seen as an influencer among the visitors to visit the collection, as observed by the volunteers:

Some visitors have watched the TV documentary and seen the bird pop out from a clock chirping. They come to the gallery wanting to see it and to know how it works. (Hall of Clocks and Watches volunteer informal discussion group, Palace Museum, Beijing)

In comparison, during the formative focus groups in the UK, the clockmaker James Cox emerged as the celebrity of the story. Cox, as a London-based producerentrepreneur creating fantastic automatons to delight an emperor in China, was a source of fascination. Empathy with an accessible albeit gifted individual stimulated interest in the many dimensions and threads of the remarkable story. However, the clocks and automatons created for the UK's trading relationship with China and the significance of James Cox were still largely unknown, even among many horologists.

\subsubsection{Demonstration of automatons}

Seeing the clocks and automatons perform is essential to engage audiences. The fragility of the clocks limits access to demonstrations of their movement, but encountering the clocks as static museum exhibits can limit visitor appreciation of their unique qualities. As noted above, findings confirm that the charm of clock movement 
stimulates significant interest among all audiences. It was evident across the three research sites that seeing the clocks was essential to engaging the non-specialist audience. Observations from volunteers who were stationed inside the Treasures of Time galleries suggest that visitors aspire to experience the automatons performing or see a screen-based version of this, as shown in the following quotes:

Visitors asked if it were possible to have animations to demonstrate movement. The film can seem too technical. Although the object was created hundreds of years ago, it was a daily object that's close to us and people use it for entertainment; it should be explained simply. (Docent focus group, HKSM)

What is shown of the clocks on the video is limited. The majority of what people see is static with just a description on the side. I think people are interested in how it works because they want to see "the magic." How does it make the bird flap its wings? Not just how the mechanism works. (Docent focus group, HKSM)

The difference between experiencing the "static" and "moving" was immeasurable. There was an evident delight and amusement when watching a demonstration. More importantly, a sense of fun prompts a greater appreciation and enjoyment of the clocks as sophisticated mechanical novelties rather than as precision timepieces. Therefore, the creation of a digital resource offers an ideal medium to demonstrate and explain movement and mechanism, and more importantly to restore the magic lost in the static display.

\subsection{Audience behavior}

There were evident behavioral differences between museum visitors according to culture and nation. In the context of attracting audiences in heritage and museum sectors, China is a nation enthusiastically rediscovering its own history and thriving on the geographic mobility of burgeoning heritage tourism (Vickers 2007). HKSM's exit survey suggests that over $50 \%$ of visitors to the Treasures of Time exhibition were from the Chinese mainland. In comparison, the potential museum audience in the UK can often seem unimpressed given the abundance of free-access museums and free shows on offer. In addition, pay-to-enter exhibitions in major UK cities are effectively and increasingly competing for visitors.

Our findings imply that Chinese visitors' attention and patience levels are greater than those in the UK. This observation is drawn from the assumption that the imperial clocks were treasures of the Chinese emperor made from precious materials, which was a common association among visitors in Hong Kong and Beijing. Although this assumption was not unique to China, it did result in greater patience with static displays and a positive response to a decorative aesthetic more appealing to Chinese taste. 
In contrast, findings from the formative focus group with young museum-goers at the Science Museum suggest that audiences in the UK often need convincing of the relevance of an exhibition about clocks. There is more evidence of "tribes" of enthusiasm, taste, and specialism where unconvinced audiences turn away from what does not instantly appeal to or what is outside the spectrum of their interests, which is in keeping with existing research (Black 2012; Falk and Dierking 2013). As a timepiece enthusiast and a watchmaker pointed out, clock collections without a compelling story can seem dull:

There are plenty of weird clocks in the Science Museum that people walk past every day. Clocks aren't that interesting for most people. (Horological specialists and timepiece enthusiasts focus group, London)

In this context, what might be described as a clock collection might seem irrelevant to those who assume this will be antique timepieces rather than fantastic automatons. The collection could be marginalized as the territory of the enthusiast, and in this context evoke associations of the elitism of luxury goods or the niche specialisms of collectable antiques.

\subsection{Expectations for a digital resource}

As established in the points above, once the visitor's curiosity is raised, there are many story threads and connections that appeal to different interests in the imperial clocks. Our findings suggest that in China, the imperial clock collection constitutes one episode in an ongoing cultural fascination with the philosophy and science of measuring time, while in the UK, interest focuses on the eighteenth century and the seventy-year "chapter" of James Cox, the trade with China and the surreal creations that emerged from a nascent relationship between two cultures. This carries implications for the creation of a digital resource that can appeal to both passionate experts and curious explorers.

On a basic level, our findings suggest that a digital resource can offer the opportunity to see all the operational clocks and automatons perform without the realtime demands of frequent demonstration by clock conservators or curators. It could also provide ongoing access to the work and restoration achievements of, for example, the Conservation Hospital in the Palace Museum. More importantly, the digital resource could enable collaboration, debate, and the sharing of academic scholarship. An emphasis on visual access and explanation through multimedia, that is, video, graphics, and simulation, will increase immediacy and appeal.

The following quotes reflect the above-mentioned aspects of expectation for a digital resource about the imperial clock collections: 
Once I saw the demonstration in the chamber with the lady working all the boxes, hearing the music, it brought all the other clocks to life. (Young international focus group, HKSM)

It needs to have instant appeal. No-one is going to surf the net to see how these clocks work. (Young international focus group, HKSM)

Because of the delicacy of the originals, it would be good to see replicas that reproduce the movement of the timepieces. It would be ideal to see the original timepiece and to have a demonstration to understand its movement at the same time. (Engineering student focus group, Beijing Jiaotong University)

More animation is needed. If it was online, something like a TED talk would be good. Explain it in one minute. Also, because the demos in the museum are only on twice a day, it would be good to have them on a screen at other times so visitors could be given a tablet, walk to a particular spot and see the demonstration or animation. (Docent focus group, HKSM)

One of the challenges of creating a digital resource is how to appeal beyond the specialist and academic enthusiast. To reach the widest possible audience, the digital resource must instantly capture the imagination and create a desire to discover and explore the remarkable collection of clocks. It is evident that seeing the movements is crucial to achieving this, as noted above. Furthermore, to appeal to the newcomer/novice, the digital resource must have instant impact on visitors. The desire to share images on social media was evident throughout gallery observations. Increasingly, QR codes are used to supplement the visitor experience, and their adoption and usage is greater in China and Hong Kong than is evident in the UK. Hence the digital resource could provide access to movement, mechanism, and backstory that enhance the encounter with the physical object through QR codes.

While the above discussions serve a practical purpose of developing a digital resource that helps visitors connect clocks to human stories and understand the clock movement, visitors' expectations of a digital resource also speak to the idea of different values being at play and how digital intervention can in fact add to the authenticity of museum collections. What do visitors find valuable about the objects and how do their values differ? As presented above, our findings confirmed that UK visitors' interest in the clocks lies in the past with James Cox, while for visitors to the Forbidden City, it lies in the present with Wang Jin. Conservation as a discipline here seems to be valued much more in China than in the UK, which is related to Chinese ideas surrounding craft and mastery well manifested through the CCTV documentary series. In reviewing the visitor comments, we are constantly reminded of an interest in the authenticity of the clocks lying in them being alive and being updated rather than being frozen in the past (Yan 2017). 


\section{Conclusion}

The imperial collection of singsongs from the Palace Museum embodies an exciting, engaging, and increasingly relevant story that has the capacity to reach a wider audience and be more than the secret preserve of the academic, enthusiast, and tourist visitor to the Forbidden City. The cultural positions of the visitors and the exhibition environment play a key role in shaping audience experience of the imperial clocks. However, audience research consistently affirms that, in all locations, connecting with human stories, seeing the clocks, and ideally experiencing them as automatons is the gateway to engagement.

The limiting description of the imperial clock collection as a "collection of historic clocks" is a reminder of the challenge when trying to capture the imagination of newcomers and non-specialist audiences. In the absence of visual examples and animation in an exhibition, the magic of clocks is lost; simple verbal and text description tend to convey a niche specialism and are likely to be the domain of the horological enthusiast, collector, and academic. It is important to note that the framing of the clocks bears importance for the marketing angle for the forthcoming Science Museum exhibition Zimingzhong 自鸣钟: Clockwork Treasures from China's Forbidden City.

A digital resource has the opportunity to be a mechanism that assists discovery of the unique singsong collection. An effective way to achieve this and meet the demands and expectations of the visitors is to provide access to both the interior and exterior of the clocks, as in filmed actuality, simulation, or animation via the digital resource. It is essential that the resource is academically robust, appealing to an international audience of specialists and experts, while at the same time having instant appeal to non-specialists and novices, and working on different levels to suit audience knowledge and interest. For example, cartoon animation can frequently bring clarity to the complex and avoid the distractions of operational machinery. In planning the digital resource, different interests should be taken into consideration when explaining and exploring the mechanisms.

While the evaluation might have been instrumentally helpful in shaping an exhibition and developing a digital resource for the imperial clocks, the audience research also adds to our growing knowledge and understanding about dialogue surrounding visitor engagement and heritage values in the museumscapes of China and the UK. Future research will be needed to evaluate how visitors to the London Science Museum engage with the forthcoming exhibition and the digital resource as legacies of the Time, Culture and Identity project. In particular, it is relevant to pursue enquiries that our current data set is not designed to provide answers for, or where it falls short, such as, "How does the visitor engage with the concept of time and different modes of time measurement?" and "What is the visitor's experience of digital 
intervention under the influence of different digital cultures, and what are the different things that visitors hold valuable in terms of their digital experience?"

\section{Acknowledgments}

I am grateful for Dr. David Francis for his honest feedback on this work. I would also like to extend my thanks to Professor Zhang Baichun 张柏春 and his team for their generous support of organizing and publishing this special issue.

\section{References}

Bain, R., and K. Ellenbogen. 2002. "Placing Objects within Disciplinary Perspectives: Examples from History and Science." In Perspectives on Object-centered Learning in Museums, edited by S. G. Paris, 140-155. Mahwah, NJ: Lawrence Earlbaum.

Ballantyne, R., K. Hughes, P. Ding, and D. Liu. 2014. "Chinese and International Visitor Perceptions of Interpretation at Beijing Built Heritage Sites." Journal of Sustainable Tourism 22 (5): 705-725.

Black, G. 2012. Transforming Museums in the Twenty-First Century. London: Routledge.

Cameron, C. M., and J. B. Gatewood. 2003. "Excursions into the Past: What People Want from Visits to Historical Sites." The Public Historian 22 (3): 107-127.

Eberbach, C., and K. Crowley. 2005. "From Living to Virtual: Learning from Museum Objects." Curator 48 (3): 317-338.

Falk, J. H., and L. D. Dierking. 2013. The Museum Experience Revisited. London: Routledge.

Fu, X., L. Cai, and X. Lehto. 2017. "Framing Chinese Tourist Motivations through the Lens of Confucianism." Journal of Travel \& Tourism Marketing 34 (2): 149-170.

Gao, J., C. Zhang, and Z. Huang. 2018. "Chinese Tourists' Views of Nature and Natural Landscape Interpretation: A Generational Perspective." Journal of Sustainable Tourism 26 (4): 668-684.

Guo, Fuxiang 郭福祥. 2013. Shijian de lishi yingxiang 时间的历史映像 [The Historical Image of Time]. Beijing: The Forbidden City Publishing House.

Hampp, C., and S. Schwan. 2015. "The Role of Authentic Objects in Museums of the History of Science and Technology: Findings from a Visitor Study." International Journal of Science Education Part B: Communication and Public Engagement 5 (2): 161-181.

He, Keyao. 2016. “What made Master in Forbidden City documentary a success?" China Daily. Last modified April 14, 2016. www.chinadaily.com.cn/culture/2016-04/14/content_24539022.htm.

Kwek, A., and Y. S. Lee. 2010. "Chinese Tourists and Confucianism." Asia Pacific Journal of Tourism Research 15 (2): 129-141.

Latham, K. F. 2013. “Numinous Experiences with Museum Objects.” Visitor Studies 16 (1): 3-20.

Leary, E., and E. C. Sholes. 2000. “Authenticity of Place and Voice: Examples of Industrial Heritage Preservation and Interpretation in the US and Europe." The Public Historian 22 (3): 49-66.

Macdonald, S., ed. 1998. The Politics of Display: Museums, Science, Culture. London: Routledge.

Pagani, C. 2001. Eastern Magnificence and European Ingenuity: Clocks of Late Imperial China. Ann Arbor: University of Michigan Press. 
Pekarik, A., Z. Doering, and D. Karns. 1999. "Exploring Satisfying Experiences in Museums." Curator 42 (2): 152-173.

Petersen, Y. Y. 1995. "The Chinese Landscape as a Tourist Attraction: Image and Reality." In Tourism in China: Geographic, Political and Economic Perspectives, edited by A. A. Lew and L. Yu, 141-154. Boulder, CO: Westview Press.

Poria, Y., A. Biran, and A. Reichel. 2009. “Visitors' Preferences for Interpretation at Heritage Sites." Journal of Travel Research 48 (1): 92-105.

Prentice, R. 2001. "Experiential Cultural Tourism: Museums and the Marketing of the New Romanticism of Evoked Authenticity." Museum Management and Curatorship 19 (1): 5-26.

Roberts, L. C. 1997. From Knowledge to Narrative: Educators and the Changing Museum. Washington, DC: Smithsonian.

Sofield, T. H. B., and F. M. S. Li. 1998. “Tourism Development and Cultural Policies in China." Annals of Tourism Research 25 (2): 362-392.

Vickers, E. 2007. "Museums and Nationalism in Contemporary China." Compare 37 (3): 365-382.

White, I. 2012. English Clocks for Eastern Markets: English Clockmakers Trading in China \& the Ottoman Empire 1580-1815. London: Antiquarian Horological Society.

Winter, T. 2009. "The Modernities of Heritage and Tourism: Interpretation of an Asian Future." Journal of Heritage Tourism 4 (2): 105-115.

Xu, H., Q. Cui, R. Ballantyne, and J. Packer. 2013. "Effective Environmental Interpretation at Chinese Natural Attractions: The Need for an Aesthetic Approach." Journal of Sustainable Tourism 21 (1): 117-133.

$\mathrm{Xu}$, H., P. Ding, and J. Packer. 2008. “Tourism Research in China: Understanding the Unique Cultural Contexts and Complexities." Current Issues in Tourism 11 (6): 473-491.

Yan, H. 2017. Heritage Tourism in China: Modernity, Identity and Sustainability. Bristol: Channel View Publications.

Yi, X., V. S. Lin, W. Jin, and Q. Luo. 2017. “The Authenticity of Heritage Sites: Tourists' Quest for Existential Authenticity, and Destination Loyalty." Journal of Travel Research 56 (8): 1032-1048.

Zhang, Xueyu 张学瑜, and Cai Qun 蔡群. 2018. “Chengjin, caibang yu zaoban: Qingdai Xiyang jixie zhongbiao ruhua yu jishu chuanbo” 呈进、采办与造办: 清代西洋机械钟表入华与技术传播 [Gifting, Purchasing, and Making: The Western Timepieces in Qing China and Their Technology Transmission]. Haiyang shi yanjiu 海洋史研究 [Studies of Maritime History] (2): 136-150. 